\title{
A « família » dos surdos-mudos face à ideia do progresso no século XIX ${ }^{1}$ \\ The "family" of deaf-mutes facing the idea of progress in the nineteenth century
}

Florence ENCREVÉ*

Universidade Paris 8

Traduzido por Rosemeri Bernieri de Souza**

Universidade Federal de Santa Catarina (UFSC)

\begin{abstract}
RESUMO: Nascida em 1834, data do primeiro banquete em honra ao abade de l'Épée, a "família" dos surdos-mudos é obra de Ferdinand Berthier (1803-1886). Ao introduzir essa tradição de banquetes, Berthier consegue federar os surdos em torno da imagem do famoso pedagogo. Em 1838, fundou a Sociedade Central dos Surdos-Mudos de Paris, composta apenas por surdos, que servia como um grupo de pressão "representativo". Berthier e seus "irmãos" surdos reivindicavam, principalmente, acesso à igualdade por meio da língua de sinais em todas as áreas da sociedade. Até 1848, eles conseguiram que suas demandas fossem ouvidas, em parte porque os franceses ainda não estavam sensíveis à ideologia do progresso. Desde a revolução de 1848 até a década de 1870, houve um declínio gradual da influência da "família" dos surdosmudos, em proporção ao crescente apoio à ideia de progresso e à sua interpretação "oralista", que triunfou em 1880 após do congresso de Milão.
\end{abstract}

PALAVRAS-CHAVE: Família dos Surdos-Mudos. Ferdinand Berthier. Progresso. Século XIX.

ABSTRACT: The deaf-mutes 'family' - the work of Ferdinand Berthier (1803-1886) - was born in 1834, when the first banquet in honnor of Abbé de l'Épée was organized. By establishing this tradition of banquets, Berthier managed to unite deaf people around the image of the famous pedagogue. In 1838, he founded the 'Société centrale des sourds-muets de Paris', entirely composed of deaf people, which became a 'representative' lobby. Berthier and his deaf

\footnotetext{
${ }^{1}$ N.T.: Tradução do artigo "La «famille» des sourds-muets face à l'idée de progrès au XIX ${ }^{\mathrm{e}}$ siècle, publicado na La Revue d'histoire du XIX ${ }^{\mathrm{e}}$ siècle", em 2013. Agradecemos à revista, representada por Emmanuel Fureux, por ter consentido sua tradução e, sobretudo, à autora que gentilmente aprovou a iniciativa. O original em francês pode ser acessado em: https://journals.openedition.org/rh19/4453.

O presente trabalho foi realizado com apoio da Coordenação de Aperfeiçoamento de Pessoal de Nível Superior - Brasil (CAPES) - Código de Financiamento 001

* Doutora em história, Mestre de conferência em Ciências da Linguagem na Universidade Paris 8 e Orientadora adjunta da Estrutura Universitária de Ciências da Linguagem na Universidade Paris 8, França.

** Doutoranda em Linguística da Universidade Federal de Santa Catarina.
} 
'brothers' demanded access to equality by sign language in all areas of society. Until 1848 they were able to make their demands heard, in part because French people were still then largely insensitives to the ideology of progress. From the Revolution of 1848 and into the 1870s, we can observe the progressive decrease of the influence of the deaf-mutes 'family', in line with the increase of the adhesion to the ideology of progress and its 'oralist' interpretation which triomphed in 1880 after the Congress of Milan.

KEYWORDS: Deaf-mutes Family. Ferdinand Berthier. Progress. 19th century.

\section{Introdução}

Por causa da exclusão social dos surdos no final do século XIX (ENCREVÉ, 2008, 2013), sua história passou a ser objeto de estudo somente a partir da década de 1970, quando eles tiveram a oportunidade de agir por conta própria, a fim de mudar sua condição. Aliás, os primeiros a se interessarem pelos surdos do século XIX não são historiadores: Bernard Mottez (2006) é sociólogo e Christian Cuxac (1983) linguista (podem ser citados também GRÉMION, 1990; DELAPORTE, 1998; BERNARD, 1999). A ausência de trabalhos históricos sobre os surdos no século XIX, pré-condição para seus estudos, levou-os a empreender, eles mesmos, essa pesquisa. No entanto, seus objetivos não eram fundamentalmente históricos e foi preciso esperar que os primeiros historiadores se debruçassem sobre o tópico, a fim de restabelecer a questão dos surdos na evolução geral da sociedade francesa do século XIX (PRESNEAU, 1998, 2010; BUTON, 1999). Entretanto, provavelmente por causa de seu status de precursores, esses trabalhos históricos buscavam, acima de tudo, estudar os surdos como objeto e não como sujeitos. É verdade que as fontes redigidas por surdos são incipientes. Com exceção de Ferdinand Berthier (1803-1886), autor de numerosos artigos e livros, os surdos que produziram textos foram principalmente os autores de relatórios dos banquetes ou das assembleias gerais das associações por ele fundadas. A apresentação do ponto de vista dos surdos-mudos no século XIX é, então, necessariamente tributária à visão de Ferdinand Berthier e de seus colegas. Suas opiniões eram representativas, principalmente, das dos Parisienses membros da "família" de surdos-mudos que fora fundada por Berthier, em 1834. Apesar disso, e de muitas maneiras, a análise da evolução dessa microssociedade pode ajudar a esclarecer, de outro modo, a evolução 
geral do século XIX, destacando particularmente o paradoxo que surge a partir da década de 1880 entre a realidade concreta vivida pelos surdos e os princípios implementados pelos republicanos em nome da liberdade e da igualdade.

\section{Observações preliminares}

Antes de entrar no cerne da questão, pode ser útil reservar um momento para debruçar-se sobre o ponto de cristalização dos conflitos entre os surdos sinalizantes e os ouvintes que eram hostis à língua de sinais no século XIX: a ideia de progresso. Para entender melhor em que medida as pessoas que decidiam e implementavam a prescrição da língua de sinais na educação dos surdos nas últimas décadas do século XIX podiam estar motivadas por uma certa interpretação da ideia de progresso, parece-nos interessante recordar os seus princípios. A ideia de progresso é conceitualizada a partir do início do século (RIOT-SARCEY, 1998) e, já no século XVIII, alguns estudiosos $(A U T I N, 1984)^{2}$ eram sensíveis ao que isso significava, mesmo que ainda não necessariamente tivesse esse nome. Como explicou François Guizot, (1829), em A História da Civilização na Europa, "A ideia do progresso, do desenvolvimento, pareceme ser a ideia fundamental contida na palavra civilização" (GUIZOT, 1851, p. 14). Segundo ele, as sociedades estão em constante progresso, tanto em termos de melhoria do bem-estar quanto da distribuição mais equitativa dos produtos desse bem-estar. Ora, o que permite uma sociedade ser chamada de "civilização" é o progresso dos indivíduos e o progresso moral da humanidade. Nessa concepção, o homem é, assim, considerado superior à natureza porque ele consegue dominá-la graças ao seu constante aprimoramento.

Os liberais, os republicanos, os industriais ${ }^{3}$, os médicos, entre outros, eram geralmente favoráveis ao progresso, assim como alguns escritores como Victor Hugo que, em 1862, escreveu:

O Progresso!

Esse grito, que damos tantas vezes, é todo o nosso pensamento; [...] O livro que o leitor tem sob os olhos neste momento é, do princípio ao fim, no seu

\footnotetext{
${ }^{2}$ Principalmente, no domínio da surdez, Jacob Rodrigues Pereire (1715-1780), cientista e inventor de um método para ensinar os surdos a falarem.

${ }^{3}$ Dos quais os irmãos Émile e Isaac Pereire, os netos de Jacob Rodrigues Pereire que, em 1875, fundaram, com Eugène Pereire (filho de Isaac), um estabelecimento de educação consagrado ao ensino da fala: a escola Jacob-Rodrigues-Pereire.
} 
conjunto e nos seus pormenores [...], a marcha do mal para o bem, do injusto para o justo, do falso para o verdadeiro, da noite para o dia, do apetite para a consciência, da podridão para a vida, da bestialidade para o dever, do inferno para o céu, do nada para Deus. Ponto de partida: a matéria; ponto de chegada: a alma. Hidra no princípio, anjo no fim (HUGO, 1862 apud HUGO, 1911, p. $165)$.

Grande parte da população passa, pouco a pouco, a aderir à ideia do progresso somente a partir da segunda metade do século, quando os primeiros efeitos concretos da 'revolução industrial' estavam sendo sentidos. Isso não significa, no entanto, que todos os franceses estivessem convencidos, pois alguns rapidamente a questionaram (BAUDELAIRE, 1972), porém pode-se dizer que, no final do século, em consequência dos progressos materiais observáveis, em particular da ciência, da técnica, da medicina, e mesmo da situação política interior, a maioria dos franceses, incluindo os próprios surdos, acreditava na melhoria contínua de sua condição tanto econômica como física.

Ora, aplicada aos surdos, essa crença se traduzia, para a maior parte dos ouvintes, na vontade de lhes permitir desfrutar dos benefícios da evolução. Para os médicos, como Jean Marc Gaspard Itard, a partir de 1800, tratava-se de tentar vários experimentos para fazê-los ouvir. Para os pedagogos, tratava-se, acima de tudo, caso não fosse possível fazê-los ouvir, capacitá-los a falar e ensiná-los a ler a fala sobre os lábios. Essa abordagem, geralmente designada como oralista, também estava ligada à falta de conhecimento da língua de sinais que culminava na tentativa de fazer com que os surdos renunciassem a prática de sua língua, a qual, entretanto, eles privilegiavam entre si e também nas suas relações com os ouvintes. Com efeito, para os surdos, a língua de sinais era um reflexo do progresso, porque somente ela lhes permitia ter acesso à totalidade do que era dito, ao contrário da leitura labial e da articulação. Para os surdos, a língua de sinais era a única maneira de serem iguais aos outros franceses. Para os médicos e pedagogos ouvintes que consideravam (sem conhecer) que a língua de sinais não permitia o desenvolvimento das faculdades intelectuais, ao contrário, era o oralismo que representava o progresso e tudo devia ser feito para permitir aos surdos de se beneficiarem dele, a fim de torná-los iguais aos ouvintes.

\section{De 1834 a 1838: a criação da "família" dos surdos-mudos na época do possível}


Ferdinand Berthier nasceu em 1803, em Louhans, e integrou a Instituição dos Surdos-Mudos de Paris como estudante em 1811. Em 1818, ele se tornou instrutor e repetidor em 1824 e, finalmente, professor em 1829, ao mesmo tempo que Alphonse Lenoir. Eles foram os dois primeiros professores surdos da Instituição Nacional dos Surdos-Mudos de Paris. Ao contrário de muitos de seus colegas que, por causa de sua surdez, não tinham acesso fácil às informações geralmente conhecidas pelos ouvintes, Ferdinand Berthier era um homem que, com grande interesse, acompanhava os acontecimentos de seu tempo. Ele mesmo era o produto da educação dos surdos como fora concebida pelo abade de l'Épée e como fora continuada pela Revolução. Graças ao ensino em língua de sinais, ele aprendeu a ler e escrever e, a seu turno, tornou-se professor. Ele era ao mesmo tempo a melhor representação do sucesso desse método e seu mais ardente defensor. Apesar disso, ele tinha consciência da vulnerabilidade da situação dos surdos, incluindo aqueles socialmente bem integrados, a partir de 1832, quando o recém-nomeado diretor da Instituição, Désiré Ordinaire, implementou a decisão tomada pelo conselho de administração de generalizar o ensino de fala articulada a todos os alunos. Essa decisão partiu principalmente do presidente do Conselho: Joseph-Marie de Gérando, famoso filantropo, do qual se pode dizer que estava inclinado à ideia de progresso. Segundo ele e Désiré Ordinaire, todos os surdos poderiam se beneficiar de todas as lições possíveis: leitura, desenhos, escrita, sinais etc., e fala. Gérando (1827, p. 399) não considerava a fala como essencial e indispensável à educação dos surdos (ele preferia a escrita), mas achava que ela devia lhes ser ensinada a fim de "despertar as ideias na mente [...] [e] transmiti-las aos outros homens". A principal consequência dessa nova organização foi a expulsão dos professores surdos dos ensinamentos gerais, por causa da incapacidade de ensinar a fala (BÉBIAN, 1834). Como parte dessa reorganização, a diretoria exigiu que cada professor ensinasse todas as lições aos mesmos alunos durante toda a sua escolaridade. Uma vez que os surdos não podiam assegurar as aulas de fala, eles foram rebaixados (de fato, não de direito) para a função de repetidores e não se beneficiavam do bônus de ensino da fala que os professores ouvintes recebiam. No entanto, os professores (surdos e ouvintes, apoiados pelos alunos) recusavam-se a implementar essa nova organização e a diretoria a abandonou em 1836 (LANE, 1996, p. 189). Essa decisão unilateral foi o gatilho que 
encorajou Ferdinand Berthier, sensível à atmosfera geral dos anos após a revolução de julho, a agir na direção da igualdade (civil) dos surdos.

Num primeiro momento, Ferdinand Berthier comprometeu-se a federar os surdos entre si. Em novembro de 1834, ele criou o Comitê dos Surdos-Mudos, composto de onze membros, todos surdos ${ }^{4}$, a fim de organizar um banquete anual que celebrava o nascimento do abade de l'Épée. Por que o abade de l'Épée? Em 1834, este último não era mais conhecido, seu método de ensino pelos sinais metódicos, muito complicado, fora abandonado pela Instituição de Paris e apenas seus ex-alunos ainda vivos se lembravam dele. Ferdinand Berthier optou por atribuir-lhe, a posteriori, o papel de ancestral mítico sob a aura do qual, agradecidos, os surdos podiam apenas se reunir. Sua imagem de ouvinte que, graças à língua de sinais, abriu as portas do conhecimento para os surdos, ilustrava particularmente bem o combate de Berthier. Trinta anos antes de estourar a Revolução de 1789, o abade de l'Épée foi o primeiro a instalar os surdos na igualdade e a reivindicá-la publicamente. Ele era um símbolo do passado, incorporando as promessas do Iluminismo que Ferdinand Berthier brandiu no intuito de marcar melhor a diferença com os ouvintes desse início do século XIX.

Desde o primeiro banquete de 1834, no qual participaram sobretudo surdos (e três ouvintes, dos quais apenas um não conhecia a língua de sinais) (MAURICE, 1934), Berthier procurou dar a conhecer a obra do abade de l'Épée. Durante todo o banquete, ele repetia aos surdos que o abade era seu "pai espiritual" (SOCIEDADE CENTRAL DE SURDOS-MUDOS DE PARIS, 1842) e os lembrava de tudo o que eles lhe deviam. Ele até convidou dois ex-alunos do abade de l’Épée para apoiar suas observações (MAURICE, 1934). E seu discurso convenceu os participantes. Os surdos fizeram vários brindes, nos quais repetiam as fórmulas de Berthier; um estrangeiro surdo tomou a palavra (em sinais) para dizer: "Meus queridos irmãos, sou italiano, aluno da escola de Turim. Aceitei com grande prazer o convite que me enviaram para assistir ao primeiro banquete celebrado na ocasião do aniversário do abade de l'Épée, nosso benfeitor" (ibidem, s/p). Todos os convidados retomaram os termos de "irmãos" e de "confraternidade", caros a Berthier. Com esse evento fundador, pode-se falar do nascimento da "família" dos surdos-mudos. Pode-se, além disso, perguntar o porquê de Berthier ter escolhido esse campo lexical para designá-la. Majoritariamente, os surdos

\footnotetext{
${ }^{4}$ Entre os quais Alphonse Lenoir e Claudius Forestier, colegas de Ferdinand Berthier.
} 
nascem em famílias ouvintes, nas quais muitas vezes são os únicos que não ouvem. Mesmo quando aprendem a falar e a fazer leitura labial, muitas vezes, eles se veem excluídos das reuniões familiares, pelo fato de ser impossível ler os lábios de várias pessoas falando ao mesmo tempo. Com frequência, era quando eles chegavam nas instituições para surdos que descobriam outros surdos, tendo como eles o sentimento de não pertencerem completamente à sua família biológica. $\mathrm{O}$ instituto então lhes parecia como uma espécie de segunda casa e os estudantes surdos como uma segunda família. Geralmente era também nessa ocasião que eles aprendiam a língua de sinais, o que lhes abria a via da compreensão do mundo ao mesmo tempo que a da comunicação sem entrave. Assim, a "família" dos surdos-mudos assumia simbolicamente o lugar que sua própria família não podia assegurar.

Todos os anos, o Comitê organizava um banquete em homenagem ao abade de l'Épée. Cada ano, em seu discurso, Ferdinand Berthier passava a retraçar a história da condição dos surdos antes do abade de l'Épée e a relatar sua vida e sua obra, particularmente, os seus aspectos mais relevantes, por ele mesmo selecionados e romantizados. Desde 1834, o Comitê declarou ter sido "encarregado" pelos

\footnotetext{
surdos-mudos de todas as instituições e de todos os países, desejosos de oferecer um tributo público de gratidão para com a memória do abade de l’Épée, seu pai, seu criador intelectual, (MAURICE, 1934, s/p)
}

para implementar esse projeto. No entanto, a "família" fundada por Berthier não pretendia ser realmente representativa da totalidade dos surdos do globo. Além do fato de que tal representação mundial era pouco realista, Berthier sabia perfeitamente que isso não necessariamente daria mais peso ao seu percurso. Em sua referência à universalidade, ele parecia preferir demonstrar que ele e seus amigos, embora formando um pequeno grupo, tinham toda legitimidade para organizar esse tributo ao abade de l’Épée, em nome de todos os surdos.

\section{De 1838 a 1848: reivindicações igualitárias ouvidas}

Em 27 de maio de 1838, Ferdinand Berthier "formalizou" os objetivos do Comitê dos surdos-mudos ao fundar a Sociedade Central dos Surdos-Mudos de Paris. 
Os membros dirigentes da associação eram basicamente os mesmos de antes, mas agora os estatutos estabeleciam a estrutura geral de suas ações, particularmente no Artigo 2:

Seu principal objetivo é deliberar sobre os interesses dos surdos-mudos em geral, para reunir em um feixe comum as luzes de todos os surdos-mudos espalhados sobre a superfície do globo, e os homens instruídos que fizeram um estudo aprofundado dessa especialidade, para estreitar os laços que unem essa grande família, para oferecer a cada um de seus membros um ponto de encontro, um centro de comunicações recíprocas e para prover-lhes facilidades de atuação no mundo (PIROUX, n. 4, 1839, p. 61).

O principal objetivo da Sociedade era dar continuidade ao empreendimento iniciado pelo Comitê de surdos-mudos: fortalecer a "família" dos surdos-mudos, sempre com uma ambição universal, e continuar a promover publicamente o trabalho do abade de l'Épée. A Sociedade Central também desejava desempenhar o papel de uma associação de caridade (com essa originalidade de ser dirigida pelos próprios surdos) e especialmente para desenvolver a educação dos surdos a fim de melhorar indiretamente sua condição (idem). No entanto, ela não teve os meios para trabalhar concretamente nessa direção. Por outro lado, ela oferecia a Ferdinand Berthier uma plataforma mais ampla do que o Comitê para divulgar suas ideias. Os resultados eram evidentes: entre 1838 e 1850 foram pintados, esculpidos e publicados (por surdos e ouvintes) um grande número de telas, estátuas e livros, cujo tema central era o abade de l’Épée. Ferdinand Berthier foi o principal promotor dessas ações e seu redator mais prolífico $(1836 ; 1840$; $1852)^{5}$. Porém, o verdadeiro sucesso dessa sociedade residia principalmente no estabelecimento de um grupo de pressão, no qual Ferdinand Berthier se apoiava para dar a conhecer as reivindicações dos surdos aos ouvintes.

É interessante notar, na constituição da família dos surdos-mudos, o papel desempenhado por um original homem das letras, Eugène Garay (1796-1873), amigo ouvinte de Ferdinand Berthier, membro do comitê consultivo da instituição de Paris, a partir de 1841. Eugène de Monglave - seu pseudônimo literário - era certamente um escritor, mas ele era acima de tudo um republicano, declarado opositor da Restauração ${ }^{6}$ e oponente cauteloso da monarquia de julho. Nascido em Bayonne, filho de um pai

\footnotetext{
${ }^{5}$ A obra de 1952, que fora redigida em 1950, foi ornada com o retrato de Michel de l'Épée gravado em talha-doce, com uma cópia de sua escrita, com o desenho de seu túmulo na igreja Saint-Roch em Paris, e com sua estátua em Versalhes.

${ }^{6}$ Ele foi condenado várias vezes como oponente do regime e era obrigado a se esconder sob diversos pseudônimos como Maurice Dufresne. Cf. Biografia das senhoras da corte e do faubourg Saint-Germain, por um camareiro dispensado, obra anônima atribuída a Eugène Garay de Monglave e Eugène-Constant Piton. Essa obra satírica foi às vezes atribuída a Vincent Founier-Verneuil. Ela foi retida, condenada e destruída pelo acórdão da Corte real de Paris em 21 de novembro de 1826.
} 
comerciante, ele era oficial da marinha antes de se lançar na carreira literária. Segundo A França literária, de 1834, ele foi membro de "várias academias francesas e estrangeiras" (QUÉRARD, 1834, parte 6, p. 206). Em 1833, foi também cofundador e secretário do Instituto Histórico de Paris. Jornalista, fundador de uma revista ${ }^{7}$, foi autor de muitos livros (MONGLAVE, 1825; 1826a; 1826b; DUFRESNE, 1830); ele também era colaborador do editor de Honoré de Balzac, Edmond Werdet (1795-1869), para o qual corrigia as obras dos autores, ou mesmo as completava em caso de falta de inspiração por parte de seus autores oficiais (MAILLARD, 1859, p. 112-13). A extensão de seus talentos literários o levou, até mesmo, a publicar, em 1834, no Jornal do Instituto Histórico, uma canção tradicional falsa sobre a batalha de Roncesvales, El Canto de Altabiscar, apresentando-o como um antigo texto anônimo que ele teria encontrado e exumado, enquanto que ele mesmo era o autor, em francês, e que havia mandado traduzir para o basco. Ora, esse procedimento não era diferente da reconstrução da imagem do abade de l'Épée por Berthier. É difícil saber qual deles influenciou mais o outro, mas, de qualquer forma, pode-se presumir que Monglave tinha sua parte nesse projeto. Sua amizade com Berthier permitia a este último ter acesso à sua agenda de endereços. Entre 1831 e 1834, Monglave participou da redação do Livro dos cento e um, notavelmente com Eugène Sue, Benjamin Constant, Victor Hugo, Afonso de Lamartine e François-René de Chateaubriand. A partir de 1834, todos esses autores eram convidados por Ferdinand Berthier aos banquetes anuais dos surdosmudos, assim como Ledru-Rollin e Victor Considérant, que Berthier - sozinho - não poderia conhecer. Parece que os dois amigos haviam descoberto interesses cruzados na constituição da família de surdos-mudos: Berthier, o apoio de celebridades, e Monglave, a oportunidade de expressar suas opiniões livremente em um ambiente fora do contexto político. Essa associação também mostra que, para alcançar os ouvintes, Berthier não poderia ter agido sozinho. Foi-lhe necessário a aprovação de um intermediário ouvinte (que ocasionalmente servia até mesmo como intérprete) para fazer com que a "voz" dos surdos fosse ouvida pelos outros ouvintes.

A Sociedade Central dos Surdos-mudos de Paris permitia que Berthier denunciasse publicamente (especialmente graças ao eco que recebia dos jornalistas) as injustiças sociais que os surdos sofriam. De fato, os surdos observavam que em muitas

\footnotetext{
${ }^{7}$ Em 1823, ele funda o jornal Le Diable boiteux, que faz reviver em 1832, depois em 1857.
} 
ocasiões eles se encontravam em situação de inferioridade na sua vida cotidiana. Por causa de sua surdez e seu uso da língua de sinais, eles não tinham a permissão de desfrutar dos direitos inscritos no Código Civil, como o casamento (SOCIEDADE CENTRAL DOS SURDOS-MUDOS DE PARIS, 1841, p. 5). Mesmo um surdo instruído podia não ser autorizado a casar se ele não falasse, embora o Código Civil não indicasse qualquer interdição em relação a ele. Ele poderia teoricamente usar francês escrito (PIROUX, n. ${ }^{\circ}$ 1, 1838, p. 5); no entanto, a jurisprudência permitia que os magistrados e subprefeitos julgassem a boa compreensão dos surdos. Ora, alguns deles não reconheciam o valor da língua de sinais ou do francês escrito e consideravam a fala como a única expressão da inteligência dos surdos. Alguns surdos instruídos eram, assim, privados do direito de se casar, direito que podia, entretanto, ser reivindicado por qualquer ouvinte, mesmo iletrado e miserável. Além disso, os membros da Sociedade Central dos Surdos-Mudos de Paris constatavam um certo a priori desfavorável em relação à moralidade dos surdos na ocasião de processo, especialmente quando se tratava de surdos não instruídos. Os magistrados, aos quais se associavam frequentemente os redatores de jornais, discutiam demoradamente, por meio da interposição de fóruns escritos, sobre o estado moral que eles pressupunham em relação aos surdos. De acordo com a maioria deles, a inteligência só podia se desenvolver pela audição e a fala, e a língua de sinais não podia alcançar o mesmo resultado (ENCREVÉ, 2011). Essas afirmações eram apenas o resultado do seu desconhecimento da língua de sinais, da qual os surdos, como Berthier e seus colegas, estavam constantemente evocando a eficiência cognitiva. De acordo com estes, os surdos eram tão conscientes da moralidade quanto os ouvintes, fossem eles instruídos ou não (PIROUX, n. 3, 1839a, p. 38). Berthier chega ao ponto de relegar o problema aos magistrados:

[...] a dificuldade da qual você se queixa não vem da inteligência do acusado, ela deve ser imputada inteiramente à inteligência do juiz" (PIROUX, 1839a, p. 39).

Na verdade, na melhor das hipóteses, essas dúvidas sobre a moralidade dos réus levava os tribunais a impor a presença de um intérprete, mesmo para os surdos instruídos, a fim de que esse mediador servisse de caução moral, intelectual e linguística. No pior dos casos, os réus eram automaticamente sentenciados sem sequer saberem do que estavam sendo acusados (SOCIEDADE CENTRAL DOS SURDOS-MUDOS DE PARIS, 1841, p. 10). Quanto aos intérpretes, eles eram muitas vezes da instituição dos surdos-mudos 
de Paris. Poderia se pensar que essa prática era um sinal de que os juízes tratavam o surdo com consideração, mas ela resultava sobretudo do fato de que em Paris a Instituição dos surdos-mudos era o único lugar onde se podia encontrar pessoas capazes de se fazerem compreendidas pelos surdos. Esses intérpretes geralmente eram professores, surdos - como Berthier, Pélissier ou Forestier, caso em que as traduções eram escritas - ou ouvintes. Quando se tratava de professores ouvintes, eles muitas vezes sabiam apenas muito superficialmente a língua de sinais. Às vezes, acontecia de eles se posicionarem a favor dos acusados (em vez de traduzir) e pediam a absolvição dos surdos manifestamente culpados em nome de sua suposta falta de discernimento entre o bem e o mal, o que Berthier não deixava de denunciar (PIROUX, n.3, 1839a, p. $35)$.

Essas constatações de inferioridade dos surdos na vida social levaram os membros da Sociedade Central dos Surdos-Mudos de Paris a reivindicar a aplicação dos princípios de 1789 aos surdos. Parece que Berthier compreendeu relativamente bem as questões da situação política sob a monarquia de julho. Ele não exigia o direito de voto para os surdos, porque, como se sabe, sua implementação não era considerada um direito, mas uma função dos liberais no poder (ROSANVALLON, 1985). Por outro lado, especialmente após a promulgação da lei de 28 de junho de 1833 sobre a educação, ele continuava a exigir a educação de todas as crianças surdas, por meio da língua de sinais, em nome da igualdade de direitos. Segundo ele, a educação era a chave para melhorar a condição dos surdos: assim que um surdo fosse instruído, ele podia conhecer seus direitos e defendê-los. Berthier, portanto, queria esclarecer os surdos, especialmente os mais pobres, graças à educação em língua de sinais e, a longo prazo, reduzir, de modo geral, as desigualdades individuais que sofriam. Entre 1838 e 1847, Ferdinand Berthier, para servir à causa dos surdos, usou um meio que correspondia bem à conjuntura política e social do momento: um grupo de pressão. Sob um regime parlamentar censitário, em que um pequeno número de pessoas representava toda a população, um único indivíduo não podia ser ouvido pela classe dirigente. Era preciso aplicar o mesmo princípio que o estabelecido pelo governo: um sistema "representativo". Essa foi a razão pela qual Berthier fundou a Sociedade Central de Surdos-Mudos de Paris, composta por surdos instruídos, e a apresente, como sendo perfeitamente legítima de se posicionar em nome de todos os surdos na França (e até 
mesmo surdos de todo o mundo). E esse método funcionou relativamente bem, uma vez que o Estado atendeu favoravelmente às reivindicações linguísticas e igualitárias dos surdos, não favorecendo particularmente o oralismo, o qual, no entanto, também beneficiava de uma condescendência por parte dos decisores. Por outro lado, o ensino da fala para os surdos também estava igualmente se desenvolvendo, sendo apoiado e incentivado pelos médicos da Instituição de Paris, primeiramente Jean Marc Gaspard Itard, no início do século, depois Alexandre Louis Paul Blanchet em 1847, e por pedagogos com diferentes concepções: para alguns, como Hector Volquin (1856, p. 11), professor de fala do Instituto de Surdos-mudos de Paris, a fala era o objetivo de seu ensino, o que autorizava a usar todos os meios existentes - incluindo a língua de sinais para conseguir isso; para outros, como Blanchet, a fala era tanto o meio como o fim da instrução. Nessa última concepção, a língua de sinais não tinha lugar como língua de ensino. Tanto os surdos como Berthier aceitavam de bom grado que os alunos aprendessem a fala, se isso fosse possível para eles em um curso complementar, quanto eles se opunham à concepção de Blanchet e outros defensores do oralismo enquanto meio ${ }^{8}$, porque, segundo eles, ele não lhes permitia ter acesso à totalidade do que era enunciado. Na primeira metade do século, o oralismo estava em processo de desenvolvimento e, se o governo não optava por uma reforma de envergadura em favor da fala, não era somente pelo fato de a própria estrutura estatal não permitir tal gênero de mudança, mas sobretudo graças às ações de Berthier e porque esse ensino especial ainda não era considerado pelos tomadores de decisão como suficientemente convincente.

\section{De 1848 a 1870: a virada em direção ao oralismo}

A "família" dos surdos-mudos foi capaz de realizar suas ambições em favor dos outros surdos, especialmente para atuar concretamente para aqueles que eram pobres e ignorantes, apenas a partir do estabelecimento da Segunda República. Certamente, em fevereiro de 1848, a revolução surpreendeu-os tanto quanto a seus contemporâneos

\footnotetext{
${ }^{8}$ Da qual, é preciso ressaltar, um surdo faz parte: Benjamin Dubois tornou-se surdo com a idade de 7 anos e era diretor da Escola de surdos-falantes Dubois filho, aberta em 1837, transferida em 1855 para a Instituição de Surdos-Mudos de Paris. Em 1868 e em 1869, Benjamin Dubois presidiu os banquetes em homenagem ao abade de l'Épée e ele fez seus discursos em língua de sinais.
} 
ouvintes, mas isso não impediu que alguns deles participassem nas insurreições. Isso é pelo menos o que eles escreveram em sua carta ao governo provisório que fora apresentada por Berthier e os membros da Sociedade Central de Surdos-Mudos de Paris, a fim de garantir o seu apoio ao novo governo (em nome de todos os surdos da França). Berthier adere sem hesitação à jovem República, mesmo que isso o levasse a criticar por meias palavras o antigo governo que, entretanto, havia lhe permitido formar seu grupo de pressão. Quaisquer que fossem seus pontos de vista políticos, ele assumia o compromisso de fidelidade a todos os novos regimes, porque ele estava, acima de tudo, apegado à causa de seus "irmãos" e também porque ele entendeu que era uma das condições do sucesso de seus projetos. Quando eles agiam como uma minoria, os surdos só podiam se comprometer com os interesses de seu único grupo. Qualquer compromisso coletivo, que não se referisse especificamente a sua causa, não era concebível para eles, porque suas reivindicações seriam, então, diluídas na defesa de interesses mais gerais. Assim, Ferdinand Berthier assumia rapidamente toda a terminologia republicana e revolucionária que ressoava no ambiente da época. Constatase uma mudança no nome do seu grupo de pressão. Diferentemente daquele de "família", Berthier usava anteriormente o termo de "fraternidade" no sentido que era concebido em 1789, proveniente do latim clássico fraternitas (relações entre irmãos, entre povos). Mas depois dos dias de junho de 1848, a palavra "fraternidade" assumiu um novo significado, mais associado à filantropia. Entretanto, Berthier não queria que os surdos estivessem muito estreitamente ligados a essa nova conotação que poderia mantê-los em um estado de inferioridade. Ao contrário, ele queria forjar uma imagem que os tornasse iguais aos ouvintes: pessoas que, graças à língua de sinais, eram capazes de tomar as decisões certas para si e para seus pares. É por isso que, desde então, ele decidiu falar de "nação" surda-muda. Esse termo, soando muito oportunamente republicano, foi provavelmente sugerido por Eugène de Monglave, porque, já em 1834, este último o usava no lugar da palavra "família" então preferida por Berthier ${ }^{9}$.

\footnotetext{
${ }^{9}$ Nas ocasiões dos banquetes de 1856, Berthier mudou de ideia sobre essa alteração, provavelmente porque lhe soava excessivamente republicano aos ouvidos do Império (cf. Sociedade Central dos SurdosMudos de Paris, parte 2, 1864, p. 124). Em 1868, Berthier empregou novamente o termo «nação à parte» (BERTHIER, 1868), mas a conjuntura sociopolítica do fim do Império e a forte escalada dos republicanos permitem explicar a reativação dessa fórmula.
} 
Após um breve ano de incerteza, os membros da Sociedade Central de SurdosMudos de Paris retomaram suas atividades. Em agosto de 1849, Ferdinand Berthier foi até condecorado com a Legião de Honra pelas mãos do Presidente da República, Luís Napoleão Bonaparte, durante a cerimônia de premiação da Instituição de surdos-mudos de Paris, o que aumentou sua notoriedade entre os ouvintes e sua popularidade entre os surdos. Os acontecimentos revolucionários de 1848 teriam permitido à família dos surdos-mudos dar um novo passo, dessa vez em favor dos mais modestos. Após a revolução, a situação política ainda incerta inspirava um sentimento de insegurança entre alguns notáveis burgueses que temiam a repetição de insurreições populares. Para se proteger contra essa ameaça, bem como para trabalhar pelos pobres, eles investiam mais do que antes em organizações de caridade. Berthier aproveitou essa oportunidade para estabelecer, em janeiro de 1850, uma segunda sociedade mista (aproximando surdos e ouvintes): a Sociedade Central de Educação e de Assistência para SurdosMudos na França, independente da Sociedade Central de Surdos-Mudos de Paris (da qual ele permaneceu presidente até sua morte em 1886). Ele insiste nessa separação porque sua primeira sociedade representava o alicerce da família de surdos e ele não queria arriscar vê-la misturar-se em uma organização dirigida principalmente por pessoas ouvintes.

Com essa segunda sociedade, Berthier expande sua ambição de agir em favor dos surdos de toda a França. Ela tinha a sua sede nas instalações da Instituição de surdos-mudos de Paris e reunia um grande número de personalidades (SOCIEDADE CENTRAL DE EDUCAÇÃO E DE ASSISTÊNCIA PARA OS SURDOS-MUDOS NA FRANÇA, 1851, p. 9): o seu presidente era Jules Dufaure, Ministro do Interior em 1848 e $1849^{10}$, e os vice-presidentes eram Charles Rémusat, deputado e ex-ministro do interior em 1840, Leon Maleville ${ }^{11}$, Ferdinand Berthier, Adolphe de Lanneau (diretor do Instituto de Surdos-Mudos de Paris), Eugene Durieu, então diretor geral dos cultos, Marie-Dominique-Auguste Sibour, arcebispo de Paris em 1848. O Barão JeanGuillaume Hyde de Neuville, ministro da Marina e das colônias em 1828-1829, era o Vice-Presidente honorário, Alphonse Lenoir era o vice-secretário e Nau-Beaupré,

\footnotetext{
${ }^{10}$ Ele era igualmente conselheiro do Estado, ministro dos Trabalhos públicos e deputado liberal sob a monarquia de julho, bem como deputado em 1848 .

${ }^{11}$ Ministro do Interior de 20 a 29 dezembro de 1848, igualmente subsecretário do Estado e deputado sob a monarquia de julho, bem como deputado de 1848 a 1851.
} 
contador do Instituto Nacional de Surdos-Mudos de Paris, o tesoureiro. No comitê das damas patronas da obra, que se encarregava das crianças menores e da vigilância dos estabelecimentos das surdas-mudas assistidas, estavam, notadamente, várias representantes da aristocracia, incluindo a baronesa de Gérando. Parece que, sem os acontecimentos do ano de 1848 , tal união em torno dos surdos não poderia ter sido tão rapidamente constituída. Pode-se questionar se uma reunião tão ampla não seria um sinal de mudança de tática por parte de Berthier, após a mudança de regime. Para convencer as autoridades, um grupo de pressão intermediário, efetivo sob a monarquia de julho, não se encaixava mais na nova conjuntura. Além disso, Monglave não fazia parte da nova sociedade. Parece que foi ele mesmo que, deliberadamente, optou por não entrar nela ${ }^{12}$, mas isso também revela que Berthier não precisava mais dele como mediador junto aos ouvintes. Como a República havia abolido o sufrágio censitário e estabelecido o sufrágio "universal", para chamar a atenção à causa dos surdos, Berthier precisou, desde então, colocar de lado sua antiga sociedade e criar uma nova estrutura: um protestante bem conhecido (Maleville), um arcebispo, um antigo legitimista ${ }^{13}$ (Hyde de Neuville), conservadores liberais ou moderados, deputados eleitos diretamente pelo povo em 1848... Ele desejava mostrar que os surdos tinham o suporte de indivíduos diferentes, "representando" de certa forma, boa parte da população, assegurando, assim, a legitimidade de sua atuação junto aos surdos.

No entanto, embora ele não quisesse assimilar a família dos surdos a essa "fraternidade filantrópica" (escolhendo, em vez disso, usar o termo "nação" para designá-la), Berthier mesmo assim recorreu a isso. Pode parecer paradoxal, uma vez que o próprio princípio de sua ação, desde 1834, foi de mostrar que os surdos deviam ser considerados iguais aos ouvintes, especialmente graças à língua de sinais. Porém, a filantropia não se destinava a tratar aqueles que se beneficiavam dela como iguais aos que a patrocinavam. Mas Berthier não tinha escolha: ele pensava nas outras pessoas surdas, naquelas que não participavam de seus banquetes e que ainda não gozavam dos benefícios da educação. Do mesmo modo, como ele reagia energicamente a cada

\footnotetext{
${ }^{12}$ Ele para até mesmo de participar dos banquetes a partir de 1853, apesar das insistências de Berthier, após as críticas da parte de alguns convidados, que se pode supor serem membros da Sociedade Central de Educação e de Assistência para os Surdos-Mudos na França (cf. Sociedade Central de Surdos-Mudos de Paris, 1842, p. 73-74).

13 NT. Os Legitimistas defendiam a volta da dinastia dita "legítima", a Casa de Bourbon, e se posicionavam contra as transformações sociais e políticas da época.
} 
revolução para assegurar o apoio dos surdos ao novo regime, Berthier usava todos os meios à sua disposição para alcançar seus objetivos, a instrução de todos os surdos pela língua de sinais, ao ponto de sacrificar, para isso, a imagem que ele queria dar dos surdos. Prudente, ele não deixava, entretanto, de apoiar a Sociedade Central dos SurdosMudos de Paris. Ele a mantinha principalmente com a prerrogativa de organizar os banquetes anuais, para os quais ele sistematicamente convidava membros ouvintes da Sociedade Central de Educação e de Assistência, tanto para mostrar-lhes que os surdos eram seus semelhantes ${ }^{14}$ como para lembrá-los da ação do abade de l'Épée em favor dos surdos.

Com essa nova sociedade, a família de surdos-mudos tinha os meios para atuar em favor dos surdos pobres. No entanto, como se tratava essencialmente de filantropia, a ambição igualitarista de Berthier não transparecia e se as situações de inferioridade eram relatadas em suas reuniões gerais, não era para encorajar o uso da língua de sinais, como fazia a Sociedade Central dos Surdos-Mudos de Paris, mas sim para mostrar a necessidade do cuidado aos surdos. Apesar de tudo, durante dez anos, a Sociedade Central de Educação e Assistência aos Surdos-Mudos na França operava de maneira relativamente homogênea, até que, no final da década de 1850, ocorreu uma mudança entre seus membros, mudança que também se produziu em muitas outras associações de caridade. Alguns dos renomados que haviam se engajado em ações filantrópicas em favor dos eventos de 1848 estavam, a partir de então, tranquilizados pelo regime estabelecido por Napoleão III depois de seu golpe de Estado e também desejavam se emancipar de sua proteção. Eles estavam gradualmente se desligando das instituições de caridade. A partir da década de 1860, os membros do conselho superior da sociedade foram progressivamente substituídos por funcionários do Ministério do Interior (que gerenciava as instituições para surdos), comerciantes, fabricantes, senhorios e exadvogados ou ex-tabeliães. Essa mudança, tão intimamente ligada aos primeiros anos do Império, reforçava a dimensão filantrópica do trabalho e completava o desaparecimento total de sua dimensão política. Ela marcou o fim da influência de Berthier e suas ideias igualitárias.

\footnotetext{
${ }^{14}$ Nas ocasiões dos banquetes, os surdos eram maioria e todos eles usavam a língua de sinais, o que surtia o efeito de "inversão" da situação habitual de comunicação e fazia os ouvintes, que não compreendiam nada da conversa, sentirem-se inferiorizados e obrigados a buscar a mediação de intérpretes ou utilizar papel e caneta para comunicar com os surdos.
} 
Berthier, no entanto, adaptou sua estratégia a essa nova conjuntura. Ele regularmente honrava Napoleão III em seus discursos e, se ele não pudesse convencer diretamente o imperador sobre a importância fundante do uso da língua de sinais pelos surdos, ele tentava tocar seus representantes: os funcionários do Império. Ele rapidamente entendeu que, para alcançar seus objetivos, ele não devia mais depender dos representantes do povo, como em 1850, mas dos representantes do poder. A partir de 1857, ele convidava para seus banquetes, principalmente, funcionários do Ministério do Interior, administradores da Instituição de Paris, bem como empresários, banqueiros e industriais, que haviam aderido a essa ideologia do progresso que o Império declarava querer promover. Mas essa adaptação não deu frutos. Percebe-se que, gradualmente, os membros da Sociedade Central de Educação e Assistência aos Surdos-Mudos na França já não consideravam a língua de sinais da mesma forma que os surdos. Ela lhes parecia resquício do passado. Nas assembleias gerais, as manifestações faladas pelos estudantes da Instituição eram mais numerosas do que as fábulas ou outros discursos expressos em língua de sinais. A corrente oralista, conduzida por pessoas convencidas de que a evolução industrial e social da França estava se movendo na direção do progresso, ganhava gradualmente mais peso. Desde o início do século, os métodos de aprendizagem da fala foram melhorados e, como resultado, as escolas para surdos abriam cada vez mais classes de articulação, mesmo aquelas mais favoráveis ao método gestual (ENCREVÉ, 2011, p. 111-115). A influência dos surdos diminuía bastante, pois suas ideias eram consideradas como indo na direção oposta à marcha do progresso. Sua opinião sobre o assunto não era mais necessária; com o passar do tempo, sua legitimidade foi substituída pela dos médicos, cientistas e professores que buscavam promover a educação dos surdos pela fala. A luta igualitarista de Berthier não ressoava suficientemente para que a situação dos surdos evoluísse na direção que ele desejava.

A Sociedade Central de Educação e Assistência aos Surdos-Mudos na França acabou escapando dos surdos, que se retiraram para a Sociedade Central dos SurdosMudos de Paris, a única estrutura em que conservam as mãos livres ${ }^{15}$. Mas como a situação política e social não era mais a mesma como havia sido na monarquia de julho,

${ }^{15}$ Ferdinand Berthier permaneceu membro do conselho de administração da Sociedade Central de Educação e de Assistência, mas ele não era mais ativo e se contentava frequentemente em fazer discursos (em língua de sinais) aos alunos da Instituição dos Surdos-Mudos de Paris, pelos quais ele exortava a serem, sobretudo, solidários entre eles. 
a Sociedade Central dos Surdos-Mudos de Paris não podia mais exercer seu papel de grupo de pressão e não era mais capaz de influenciar as autoridades. Em 1867, Berthier decidiu renomeá-la: Sociedade Universal dos Surdos-Mudos, provavelmente para melhor marcar sua diferença com a outra sociedade e para mostrar que os surdos queriam recuperar o controle do que lhes dizia respeito. No entanto, essa sociedade composta apenas por surdos não conseguiu conter a onda oralista que, em nome do progresso, vinha sobre eles. Tudo o que restava para Berthier era educar os surdos ele mesmo. Em 1868, ele publicou Le Code Napoleon, código civil do Império Francês, disponível para os surdos-mudos, suas famílias e os falantes no relacionamento diário com eles. $\mathrm{Na}$ introdução, ele especificou que seu livro fora escrito para surdos, para tornar-lhes o direito acessível, para que eles conhecessem melhor as leis e especialmente aquelas que lhes diziam respeito. O fim do Império e a proclamação da República poderiam ter lhe dado uma nova oportunidade para provocar a evolução de sua estratégia e talvez obter melhores resultados, mas ele estava velho e parece que não havia encontrado o provável sucessor para retomar sua luta com o mesmo sucesso e a mesma energia que ele.

Em 1880, após o Congresso de Milão (ENCREVÉ, 2008), segundo congresso internacional para a melhoria do destino dos surdos-mudos, o governo decidiu reformar a educação dos surdos em torno da aplicação do método chamado oral "puro", proibindo a língua de sinais. Os republicanos aderiram fortemente a ideia de progresso e essa reforma também era, segundo eles, uma forma de implementar o princípio "universal" da igualdade. Para eles, a igualdade residia na identidade e não na diferença, mas a identidade em relação à sua própria "norma", a dos (homens) ouvintes ${ }^{16}$. Paradoxalmente, essa interpretação levou-os a excluir da igualdade todos aqueles que não correspondiam a essa norma. Ao proscrever a língua de sinais, eles queriam oferecer aos surdos uma igualdade de meios com todos os outros franceses, a fim de permitir que eles se aproximassem o máximo possível do padrão ouvinte-falante. Como os surdos não são ouvintes, essa reforma produziu o efeito de inferiorizá-los. Os adultos surdos não eram mais admitidos em profissões intelectuais como antes, incluindo a de

\footnotetext{
16 Os progressos da medicina e da ciência, cujos promotores estavam persuadidos que um dia conseguiriam curar os surdos e fazer desaparecer todas as "anormalidades", serviam de caução científica à validade "universal" dessa norma.
} 
professor para surdos: os últimos professores da Instituição de Surdos de Paris foram demitidos em 1887. E as crianças surdas eram categorizadas de acordo com sua aptidão de se beneficiar do ensino da fala, ou seja, mais ou menos em função do seu grau de audição. Os mais surdos eram qualificados como "inaptos" ou mesmo "atrasados", justificando, assim, a criação de um ramo "anormal" da psicologia, sendo automaticamente removidos das instituições educacionais. Os menos surdos eram considerados educáveis pela fala, mas apenas capazes de realizar trabalhos manuais que não requeriam comunicação com ninguém. A inferioridade dos surdos foi institucionalmente legitimada pela interpretação republicana da universalidade dos princípios de 1789. Apesar das boas intenções daqueles que afirmavam que a fala articulada ia na direção do progresso e que a língua de sinais era sua antítese, a sociedade evoluiu aos olhos da "família" dos surdos-mudos no sentido contrário.

\section{REFERÊNCIAS}

BIOGRAPHIE des dames de la cour et du faubourg Saint-Germain, par un valet-dechambre congédié. Obra anônima atribuída a Eugène Garay de Monglave, EugèneConstant Piton, Paris: Les marchands de nouveautés, 1826.

AUTIN, J. Les frères Pereire, le bonheur d'entreprendre. Paris: Librairie académique Perrin, 1984.

BAUDELAIRE, C. Les fleurs du mal. Paris: Gallimard, 1972 [1857].

BÉBIAN, A. Examen critique de la nouvelle organisation de l'enseignement dans l'Institution royale des sourds-muets de Paris. Paris, Treuttel et Wurtz: Hachette, 1834.

BERNARD, Y. Approche de la gestualité à l'institution des sourds-muets de Paris, aux XVIIIe et XIXe siècles. 1999. Tese (Linguística). Paris, Universidade de Paris. Orientação de Frédéric François. (Universidade Paris 5,).

BERTHIER, F. Histoire et statistique de l'éducation des sourds-muets. Paris: Do autor ou da administração do Instituto histórico, 1836.

Les sourds-muets avant et depuis l'abbé de l'Épée. Paris: Ledoyen, 1840. 
L'abbé de l'Épée, sa vie, son apostolat, ses travaux, sa lutte et ses succès, avec l'historique des monuments élevés à sa mémoire à Paris et à Versailles. Paris: Michel Lévy frères, 1852.

Le Code Napoléon, code civil de l'Empire français mis à la portée des sourdsmuets et de leurs familles et des parlants en rapport journalier avec eux. Paris: Librairie du Petit journal, 1868.

BUTON, F. Les corps saisis par l'État, l'éducation des sourds-muets et des aveugles au XIXe siècle. Contribution à la socio-histoire de l'État (1789-1885). 1999. Tese (Ciências Sociais. Orientação de Michel Offerlé, Escola de estudo superior em Ciências Sociais, 1999.

CUXAC, C. Le langage des sourds. Paris: Payot, 1983.

DELAPORTE, Y. Le regard sourd "Comme un fil tendu entre deux visages...". Terrain, n. 30, p. 49-66, mar. 1998.

DUFRESNE, M. Le Bourreau. Paris: E. Renduel, 1830.

ENCREVÉ, F. Sourds et société française au XIXe siècle (1830-1905). Tese em História sob a orientação de Michèle Riot-Sarcey e de Christian Cuxac - Universidade Paris 8, Paris, 2008.

Réflexions sur le congrès de Milan et ses conséquences sur la langue des signes française à la fin du XIXe siècle. Le Mouvement Social. Paris, La Découverte, n. 223, p. 83-98, abr.-jun, 2008.

Les sourds dans la société française. Idée de progrès et langue des signes. Paris: Grâne, Créaphis, 2013.

De l'abbé de l'Épée à l'abbé Tarra, La "conversion" des ecclésiastiques catholiques à la méthode orale dans l'éducation des sourds (1760-1880). Revue d'histoire de l'Église de France, .v. 97, n. 238, p. 103-120, jan.jun. 2011.

GÉRANDO, J-M. De l'éducation des sourds-muets de naissance. Tome 2. Paris: Méquignon l'âné, 1827.

GRÉMION, J. La planète des sourds. Sylvie Messinger, 1990.

GUIZOT, F. Histoire de la civilisation en Europe depuis la chute de l'Empire romain. 6. édition. Paris: Masson, 1851.

LANE, H. Quand l'esprit entend, Histoire des sourds-muets. Paris, Odile Jacob, 1996. 
MAURICE, B. Comité des Sourds-Muets. Registre des présents aux banquets. Le Temps, Paris, n. 1872, 2 dez. 1834.

MAILLARD, F. Histoire anecdotique et critique de la presse parisienne), $2 \mathrm{e}$ et $3 \mathrm{e}$ années, 1857 et 1858. Revue des journaux de l'année, Paris, Poulet-Malassis et de Broise, 1859.

MONGLAVE, E. G. Histoire de l'Espagne. Paris: Raymond, 1825.

Biographie pittoresque des quarante de l'Académie française, par le portier de la maison. 1re édition, revue et corrigé par un de ces messieurs et suivie de l'histoire des quarante fauteuils. Paris: Les marchands de nouveautés, 1826a.

Histoire de la Suisse. Paris: Dauthereau, 1826b.

MOTEZ, B. Les Sourds existent-ils ?. Textos reunidos e apresentados por Andrea Benvenuto. Paris: L'Harmattan, 2006.

PIROUX, J. L'ami des sourds-muets, journal de leurs parents et de leurs instituteurs, utile à toutes les personnes qui s'occupent d'éducation. Paris: Hachette, n. 1, nov. 1838. L'ami des sourds-muets, journal de leurs parents et de leurs instituteurs, utile à toutes les personnes qui s'occupent d'éducation. Paris: Hachette, n. 3, jan. 1839a.

. L'ami des sourds-muets, journal de leurs parents et de leurs instituteurs, utile à toutes les personnes qui s'occupent d'éducation. Paris: Hachette, n. 4, fev. 1839b.

PRESNEAU, J. R. Signes et institutions des sourds XVIIIe -XIXe siècles. Seyssel: Champ Vallon, 1998.

L'éducation des sourds et muets, des aveugles et des contrefaits au siècle des Lumières (1750-1789). Paris: L’Harmatttan, 2010.

QUÉRARD, J-M. La France littéraire ou dictionnaire bibliographique des savants, historiens et gens de lettres de la France, ainsi que des littérateurs étrangers qui ont écrit en français, plus particulièrement pendant les XVIIIe et XIXe siècle. Paris: Didot, 1834.

RIOT-SARCEY, M. Le réel de l'utopie, Essai sur le politique au XIXe siècle. Paris: Albin Michel, 1998.

ROSANVALLON, P. Le moment Guizot. Paris: Gallimard, 1985. 
SOCIÉTÉ CENTRALE DES SOURDS-MUETS DE PARIS. Banquets des sourdsmuets réunis pour fêter les anniversaires de la naissance de l'abbé de l'Épée. Parte 1. Paris: Ledoyen, 1842.

. Résumé des travaux pendant l'année 1840-1841. Paris, A. René e Cie, 1841.

Banquets des sourds-muets réunis pour fêter les anniversaires de la naissance de l'abbé de l'Épée, 1849-1863. Paris, Hachette, 1864.

SOCIÉTÉ CENTRALE D’EDUCATION ET D’ASSISTENCE POUR LES SOURDSMUETS EN FRANCE. Première séance générale annuelle, tenue sous la présidence de M. Dufaure, membre de l'Assemblée nationale, président de la Société., 13 mar. 1851. Paris: Thunot et Cie, 1851.

VICTOR HUGO. Les misérables: Parte 4. Paris: Nelson, 1911.

VOLQUIN, H. L'impartial, journal de l'enseignement des sourds-muets. Paris: Baillière, 1856. 